\title{
Transcatheter pulmonary valve replacement in native and nonconduit right ventricle outflow tracts
}

\author{
Paul Tannous, MD, PhD, and Alan Nugent, MBBS
}

Feature Editor's Introduction-Only 2 years ago, I wrote an editorial about transcatheter pulmonary valve insertion and commented that this was a, new paradigm. ${ }^{1}$ Successful transcatheter pulmonary valve insertion had been reported in 100 patients where the previous surgically placed bioprosthetic pulmonary valve was used as a landing zone. ${ }^{2}$

The following excellent Invited Expert Opinion gives us a current update on the relatively new frontier of tanscatheter pulmonary valve insertion in native and nonconduit right ventricular outflow tracts. This is the next new paradigm where there is no need for a previously placed, landing zone! The authors have given us a perspective on the interventionalist's current thinking and approach to native outflow tract transcatheter pulmonary valve insertion. They discuss the limitations of the currently available devices and technologies that are likely to become available in the near term in the United States.

Clearly, a great deal of progress has occurred over the past 5 to 10 years and this progress is accelerating. This is an exciting time with multiple device developments at varying stages of clinical trials. Perhaps we are approaching a time when it may be possible to counsel parents of new babies with tetralogy of Fallot that the initial tetralogy repair will be the only (last) operation. By the time these children require a pulmonary valve replacement it may be that transcatheter insertion in the native or surgically patched outflow tract will be the standard of care.

Of course, these newer modalities will need to be carefully compared with the proven track record of transcatheter valve placement in an extraordinarily safe landing zone (ie, prior surgically placed bioprosthetic valve). The superb

\footnotetext{
From the Division of Cardiology, Department of Pediatrics, Ann \& Robert H. Lurie Children's Hospital of Chicago and Northwestern University Feinberg School of Medicine, Chicago, Ill.

Received for publication March 17, 2020; revisions received July 17, 2020; accepted for publication July 27, 2020; available ahead of print Sept 15, 2020.

Address for reprints: Paul Tannous, MD, PhD, Division of Cardiology, Department of Pediatrics, Ann \& Robert H. Lurie Children's Hospital of Chicago and Northwestern University Feinberg School of Medicine, 225 E Chicago Ave, Box 21, Chicago, IL 60611 (E-mail: ptannous@luriechildrens.org).

J Thorac Cardiovasc Surg 2021;162:967-70

$0022-5223 / \$ 36.00$

Copyright (c) 2020 by The American Association for Thoracic Surgery

https://doi.org/10.1016/j.jtcvs.2020.07.126
}

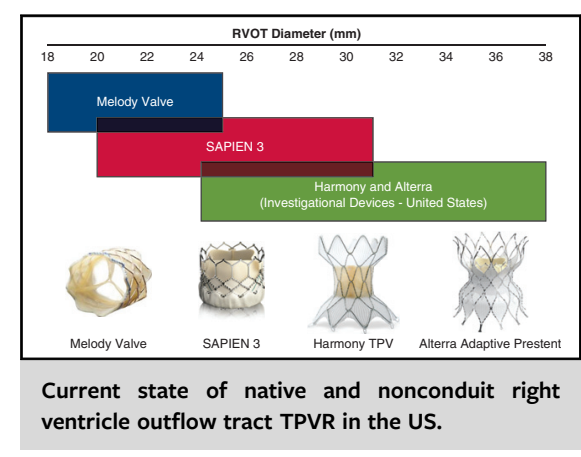

\section{CENTRAL MESSAGE \\ Twenty years of innovation in transcatheter pulmonary valve replacement.}

This Invited Expert Opinion provides a perspec tive on the following paper: J Am Coll Cardiol Intv. 2018; 11:1642-1650. https://doi.org/10.1016/j. jcin.2018.05.051.

See Commentaries on pages 971,972 , and 973

results with what is now the old paradigm will have to be carefully compared with the new paradigm. The ultimate flight plan for a baby born with tetralogy of Fallot will continue to evolve and require careful communication between surgeons and interventional cardiologists.

\section{Carl L. Backer, MD}

Dysfunction of the right ventricle outflow tract (RVOT) and pulmonary valve are some of the most commonly encountered lesions in pediatric and adult congenital heart disease. Tetralogy of Fallot is the quintessential RVOT anomaly and the most common form of cyanotic congenital heart disease. ${ }^{3}$ Technique of surgical repair largely depends on the native anatomic substrate; approximately $80 \%$ of patients with tetralogy of Fallot present with pulmonary stenosis and undergo either a valve-sparing repair or transannular patch. The other $20 \%$ are born with pulmonary atresia and surgical repair requires a RV to pulmonary artery (RVPA) conduit. Long-term durability remains an issue with RV dysfunction caused by pulmonary insufficiency and RV volume 
overload; pulmonary valve stenosis causing a pressureloaded RV; or, mixed dysfunction with characteristics of both.

Surgery was the only option for pulmonary valve replacement (PVR) until a paradigm shift occurred in 2000 when Bonhoeffer and colleagues ${ }^{4}$ performed the first in human transcatheter PVR (TPVR) in a dysfunctional RVPA conduit. The technology was subsequently refined and taken to market as the Melody Transcatheter Pulmonary Valve (Medtronic Inc, Minneapolis, Minn), receiving its $\mathrm{CE}$ mark (indicating that the product meets all the requirements of the relevant recognized European harmonized performance and safety standards) in 2006. In the United States, the Melody Valve received Food and Drug Administration humanitarian device exemption in 2010, approval for conduit dysfunction in 2015, and approval for implant in failed bioprosthetic pulmonary valves (BPVs) in 2017. The TPVR toolkit was further expanded in 2016 with Food and Drug Administration approval of the Sapien XT valve (Edwards Lifesciences, Irving, Calif) for RVPA conduit dysfunction. The Sapien valve line was designed for the aortic position, but the latest iteration the Sapien 3 has increased applicability to the pulmonary position and is currently undergoing clinical trial. Three- to 7-year results for on-label use of Melody and Sapien valves have been published and demonstrate durable valve function with good hemodynamic parameters. ${ }^{5-7}$ Despite this early success, RVPA conduits and BPVs only comprise an estimated $20 \%$ of all RVOT reconstructions.

To address this gap in care, interventionalists are increasingly using Melody and Sapien valves off-label for implantation in native and nonconduit postsurgical RVOTs. ${ }^{8,9}$ In 2018, Martin and colleagues ${ }^{10}$ published among the largest series to date, discussing attempted Melody implants in 229 patients from 11 centers in the United States and Canada. They report a 58\% success rate with excellent postintervention hemodynamic parameters and valve function, and a median hospital stay of 1 day. However, a $42 \%$ failure-toimplant rate is not insignificant. Of the 83 patients meeting criteria for TPVR, the primary reasons for implant failure were RVOT diameter exceeding Melody valve capacity (62 patients), aortic root compression (11 patients), and coronary artery compression (10 patients). They report that no implants were performed in patients with RVOT dimensions $>22 \times 23 \mathrm{~mm}$ on precath cross-sectional imaging. The importance of the study by Martin and colleagues ${ }^{10}$ is 2-fold; it demonstrates the feasibility of TPVR in the native RVOT, and that the primary limitation is implant diameter. Limited applicability is further highlighted by the fact that in this multicenter study, a high-volume center ( $>20$ patients in a 6.5 -year study) equates to approximately 3 patients per year.

The Melody valve has a rated outer diameter of $24 \mathrm{~mm}$, with capacity for overdilation to reach a maximum diameter of $25 \mathrm{~mm} .{ }^{11}$ The Sapien valve line has nominal dimeters up to $29 \mathrm{~mm}$ and can be overdilated to $31 \mathrm{~mm} .{ }^{12}$ Multiple reports now document excellent outcomes using the Sapien XT and Sapien 3 valves in outflow tracts larger than $24 \mathrm{~mm} \cdot{ }^{6,8,13}$ Although use of valves off label does not completely resolve the issue of implantation in dilated outflow tracts, it does open the possibility of TPVR to a larger number of patients with RV dysfunction.

Considering the size, heterogeneity, and dynamic nature of the RVOT, it is unlikely that any modification of balloon expandable valves will adequately address the needs of about two-thirds of this patient population. The next generation of devices are self-expanding, hourglass frames designed to stably position in the dilated RVOT. Two devices are currently undergoing trial within the United States: Medtronic has developed the Harmony TPV (Medtronic Inc, Minneapolis, Minn), which is a porcine pericardial tissue valve mounted within a self-expanding covered nitinol frame sewn onto a polyester fabric tube. ${ }^{14}$ The Harmony TPV 22 and 25 have inflow/outflow diameters of $42 /$ $34 \mathrm{~mm}$ and 54.4/43.5 mm, respectively. Harmony TPV 22 has published 3-year follow-up ${ }^{15}$ and results for Harmony TPV 25 are eagerly awaited. ${ }^{16}$ Edwards Lifesciences has developed the Alterra Adaptive Prestent, also an hourglass shaped, self-expanding covered nitinol frame with inflow/ outflow diameters of $40 \mathrm{~mm}$ suitable for outflow tracts measuring 27 to $38 \mathrm{~mm}$. Unlike Harmony, the Alterra functions as a docking site for subsequent deployment of a $29 \mathrm{~mm}$ Sapien 3 valve. The Venus P valve (Venus Medtech, Shanghai, China) is a self-expanding trileaflet porcine pericardial valve on a laser cut nitinol frame. This product line, not available in the United States but undergoing clinical trials in Europe and Asia, is applicable for RVOTs up to $34 \mathrm{~mm}^{17}$

Although multiple devices have been developed for patulous RVOTs and are undergoing trials, the reality is the variable RVOT anatomy means any device that is applicable to even $50 \%$ of patients is doing well. The number of patients screened for the above trials and the number of actual implants highlights the difficulty of percutaneous valve design in such variable anatomy. ${ }^{18}$ For example, the Venous P Valve has multiple sizes and lengths, compared with 2 Harmony devices and 1 Alterra device, and thus arguably will be applicable to a wider proportion of patients. At this time, the long-term follow-up on all self-expanding valves in the native and nonsurgical RVOT is limited, but valves designed for this patient cohort will be on the market sooner rather than later.

Procedural complications continue to challenge the interventional field. Severe adverse events include (but are not limited to) disruption of noncompliant conduits, valve malposition/embolization potentially requiring urgent surgical retrieval, and tricuspid valve injury. ${ }^{13,19}$ Mortality is a rare occurrence with a reported rate of $0.2 \%$ to $0.8 \%{ }^{20}$ 
Implantation is aborted in up to $10 \%$ of patients due to coronary and/or aortic compression. Noninvasive imaging techniques are anticipated that will better predict the compliance of the landing zone as well as coronary and aortic compression. Loss of stent integrity (fractures) occurred in $32 \%$ of implants in early prospective trials, but this risk has been significantly decreased with prestenting of Melody valves, which has now become a standard practice. ${ }^{21}$ Stent fractures have not been reported with the Sapien valve lines. Promising 1-year results from the Congenital Multicenter Trial of Pulmonic Valve Dysfunction Studying the SAPIEN 3 Interventional Transcatheter Heart Valve (COMPASSION S3) trial involving implant in conduits or BPVs were recently presented in abstract form; 58 patients were included and at 1 year there was no mortality, endocarditis, triscuspid valve injury, or valve malposition. ${ }^{22}$

The most concerning and widely publicized post-implant complication remains infective endocarditis of the transcatheter valve with clinical presentations ranging from nondescript malaise to fulminant sepsis involving RV and multiorgan failure. Kaplan-Meier curves from the longest prospective analyses include 3 multicenter Melody studies demonstrates an annualized rate of endocarditis at $3.1 \%$ per patient-year, and TPV-related endocarditis at 2.4\% per patient-year. Risk factors for infective endocarditis included residual gradients post-TPVR $>15 \mathrm{~mm} \mathrm{Hg}$ and younger age $(<12$ years $) .^{23}$

It is important to note that the performance and adverse event data cited above are almost exclusively derived from studies looking at TPVR in dysfunctional conduits and BPVs, not implantation in the native RVOT. Because of this limitation in data, adverse event and infective endocarditis rates for TPVR in the native and nonsurgical RVOT remain largely unknown. It seems a reasonable hypothesis that infective endocarditis risk would be proportional to total burden of foreign material; that is, a valve implanted within a degenerated conduit would convey greater risk than a valve implanted in native tissue, but this remains to be demonstrated or refuted by any meaningful data.

Similarly, the long-term ( $>10$ year) function of native outflow tract percutaneous valves compared with surgical valves will only be answered with time. However, the traditional end point of reintervention is inadequate as meaningful valve dysfunction occurs long before replacement, and with continually expanding transcatheter options the threshold for reintervention in the setting of surgical or transcatheter valve dysfunction is constantly changing. Considering the diameters involved in native RVOT implants, we anticipate that most patients will be candidates for 1 , or even more, valve-in-valve TPVR.

There is a clear physical and psychological preference from the patient perspective for percutaneous valves and a well-designed, prospective study demonstrating noninferiority would suffice for the percutaneous option to be the preference. Until these data exist, it is contingent on cardiologists, interventionalists, and surgeons to educate patients on the known and unknown risks and benefits of each approach. It is our protocol at Lurie Children's to review native outflow tract cases at our multidisciplinary care conference to ensure that all opinions have been expressed. The summary opinion is then discussed with the patient, who is also offered a direct consult with both the surgical and interventional teams.

It is unusual for the early generation designs of any device to become the final product. TPVs are no different and over the past 20 years there has been rapid development in available technologies and technical expertise related to TPVR. Before the year 2000, there were no transcatheter options for PVR, but as of this writing there are more than 14,000 Melody Valve implants alone. Despite this success, today most patients still do not have on-label options. If industry continues to invest similarly over the next 2 decades, and the technological advances continue at current pace, it is likely that TPVR will become an option for most patients with RV dysfunction.

\section{Conflict of Interest Statement}

Dr Nugent holds US patent No. 7,470,285 (12/30/2008, filed 2/7/2005). Dr Tannous reported no conflicts of interest.

The Journal policy requires editors and reviewers to disclose conflicts of interest and to decline handling or reviewing manuscripts for which they may have a conflict of interest. The editors and reviewers of this article have no conflicts of interest.

\section{References}

1. Backer CL. Pulmonary valve replacement: a new paradigm. J Thorac Cardiovasc Surg. 2018;155:1710-1.

2. Cabalka AK, Asnes JD, Balzer DT, Cheatham JP, Gillespie MJ, Jones TK, et al. Transcatheter pulmonary valve replacement using the Melody valve for treatment of dysfunctional surgical bioprostheses: a multicenter study. J Thorac Cardiovasc Surg. 2018;155:1712-24.

3. Parker SE, Mai CT, Canfield MA, Rickard R, Wang Y, Meyer RE, et al. Updated National Birth Prevalence estimates for selected birth defects in the United States, 2004-2006. Birth Defects Res A Clin Mol Teratol. 2010;88:1008-16.

4. Bonhoeffer P, Boudjemline Y, Saliba Z, Merckx J, Aggoun Y, Bonnet D, et al. Percutaneous replacement of pulmonary valve in a right-ventricle to pulmonary-artery prosthetic conduit with valve dysfunction. Lancet. 2000;356: 1403-5.

5. Cheatham JP, Hellenbrand WE, Zahn EM, Jones TK, Berman DP, Vincent JA, et al. Clinical and hemodynamic outcomes up to 7 years after transcatheter pulmonary valve replacement in the US Melody valve investigational device exemption trial. Circulation. 2015;131:1960-70.

6. Haas NA, Carere RG, Kretschmar O, Horlick E, Rodes-Cabau J, de Wolf D, et al. Early outcomes of percutaneous pulmonary valve implantation using the Edwards SAPIEN XT transcatheter heart valve system. Int J Cardiol. 2018;250: 86-91.

7. Kenny D, Rhodes JF, Fleming GA, Kar S, Zahn EM, Vincent J, et al. 3-year outcomes of the Edwards SAPIEN transcatheter heart valve for conduit failure in the pulmonary position from the COMPASSION multicenter clinical trial. JACC Cardiovasc Interv. 2018;11:1920-9.

8. Hascoet S, Dalla Pozza R, Bentham J, Carere RG, Kanaan M, Ewert P, et al. Early outcomes of percutaneous pulmonary valve implantation using the Edwards SAPIEN 3 transcatheter heart valve system. EuroIntervention. 2019;14:1378-85. 
9. Meadows JJ, Moore PM, Berman DP, Cheatham JP, Cheatham SL, Porras D, et al. Use and performance of the Melody transcatheter pulmonary valve in native and postsurgical, nonconduit right ventricular outflow tracts. Circ Cardiovasc Interv. 2014; 7:374-80.

10. Martin MH, Meadows J, McElhinney DB, Goldstein BH, Bergersen L, Qureshi AM, et al. Safety and feasibility of Melody transcatheter pulmonary valve replacement in the native right ventricular outflow tract. JACC CardiovasC Interv. 2018;11:1642-50.

11. Cheatham SL, Holzer RJ, Chisolm JL, Cheatham JP. The Medtronic Melody(R) transcatheter pulmonary valve implanted at 24-mm diameter-it works. Catheter Cardiovasc Interv. 2013;82:816-23.

12. Kodali S, Thilo C, Ott I, Schunkert H, von Scheidt W. Overexpansion of the SAPIEN 3 transcatheter heart valve: a feasibility study. JACC Cardiovasc Interv. 2015;8:2041-3.

13. Sinha S, Aboulhosn J, Asnes J, Bocks M, Zahn E, Goldstein BH, et al. Initial results from the off-label use of the SAPIEN S3 valve for percutaneous transcatheter pulmonary valve replacement: a multi-institutional experience. Catheter Cardiovasc Interv. 2019;93:455-63.

14. Bergersen L, Benson LN, Gillespie MJ, Cheatham SL, Crean AM, Hor KN, et al. Harmony feasibility trial: acute and short-term outcomes with a selfexpanding transcatheter pulmonary valve. JACC Cardiovasc Interv. 2017;10: $1763-73$.

15. Benson LN, Gillespie MJ, Bergersen L, Cheatham SL, Hor KN, Horlick EM, et al. Three-year outcomes from the Harmony native outflow tract early feasibility study. Circ Cardiovasc Interv. 2020;13:e008320.

16. The Medtronic Harmony Transcatheter Pulmonary Valve Clinical Study. NML identifier: NCT 02979587. Available at: https://clinicaltrials.gov/ct2/show/ NCT02979587. Accessed March 12, 2020.

17. Morgan G, Prachasilchai P, Promphan W, Rosenthal E, Sivakumar K, Kappanayil M, et al. Medium-term results of percutaneous pulmonary valve implantation using the Venus P-valve: international experience. EuroIntervention. 2019; 14:1363-70.

18. Schievano S, Coats L, Migliavacca F, Norman W, Frigiola A, Deanfield J, et al. Variations in right ventricular outflow tract morphology following repair of congenital heart disease: implications for percutaneous pulmonary valve implantation. J Cardiovasc Magn Reson. 2007;9:687-95.

19. Faccini A, Butera G. Tricuspid regurgitation as a complication of Edwards Sapien XT valve implantation in pulmonary position a problem to deal with. Catheter Cardiovasc Interv. 2018:91:927-31.

20. Goldstein BH, Bergersen L, Armstrong AK, Boe BA, El-Said H, Porras D, et al. Adverse events, radiation exposure, and reinterventions following transcatheter pulmonary valve replacement. J Am Coll Cardiol. 2020;75: 363-76.

21. Cabalka AK, Hellenbrand WE, Eicken A, Kreutzer J, Gray RG, Bergersen L, et al. Relationships among conduit type, pre-stenting, and outcomes in patients undergoing transcatheter pulmonary valve replacement in the prospective North American and European Melody Valve trials. JACC Cardiovasc Interv. 2017;10: 1746-59.

22. Babaliaros VC. One-year results from the COMPASSION S3 trial: treatment of patients with a dysfunctional right ventricular outflow tract (RVOT) conduit or previously implanted pulmonic valve with the SAPIEN 3 transcatheter heart valve. Presented at: SCAI 2020 Scientific Sessions; May 15, 2020; Atlanta, GA.

23. McElhinney DB, Sondergaard L, Armstrong AK, Bergersen L, Padera RF, Balzer DT, et al. Endocarditis after transcatheter pulmonary valve replacement. J Am Coll Cardiol. 2018;72:2717-28.

Key Words: transcatheter pulmonary valve, native right ventricular outflow tract, congenital heart disease 